\title{
Choroid Plexus of the Lateral Ventricle
}

National Cancer Institute

\section{Source}

National Cancer Institute. Choroid Plexus of the Lateral Ventricle. NCI Thesaurus. Code C32309.

A vascular fringe projecting from the choroidal fissure into each lateral ventricle where cerebrospinal fluid is produced. 